\title{
Vikram Sarabhai: his vision of India as a space power and its fulfilment
}

\author{
R. Aravamudan* \\ K5/3, 10th Cross, RMV Extension, Sadashivanagar, Bengaluru 560 080, India
}

Born a hundred years ago, Vikram Sarabhai was a man of many dimensions. He was a real visionary, an outstanding scientist, a great institution builder and a true patriot, who wanted to bring about the rapid development of India by making use of the most modern technological tools of the day.

Vikram was the scion of a family well known for industrial excellence. He was born with an aptitude for scientific enquiry, which he successfully coupled with his innate talent for enterprise and innovation. Many were the institutions which he envisioned and brought to successful realization. However, I would name making India a space power, as his first love. He was convinced that India can 'leap frog' over decades of scientific and industrial backwardness by using the tools of the latest advances in space science and technology, particularly in areas like communication, education, health, planning, disaster management and optimal resource utilization by remote sensing techniques. With his extensive contacts in the world scientific community and policy makers, he was able to convey and convince the decision makers of the urgency of taking active steps to achieve this and invest adequate resources for this purpose.

In a speech made by him at the Thumba Equatorial Rocket Launching Station in February 1968 Vikram Sarabhai said:

'There are some who question the relevance of space activities in a developing nation. To us, there is no ambiguity of purpose. We do not have the fantasy of competing with the economically advanced nations in the explorations of the moon or the planets or manned space flight. But we are convinced that if we are to play a meaningful role nationally, and in the comity of nations, we must be second to none in the application of advanced technologies to the real problems of man and society, which we find in our country. And we should note that the application of sophisticated technologies and methods of analysis to our problems is not to be confused with embarking on grandiose schemes, whose primary impact is for show rather than progress measured in hard economic and social terms.'

\footnotetext{
*e-mail: aravamudan37@gmail.com
}

If a centenarian Sarabhai were alive today and he surveyed the state of space technology in India, this is what he would see.

From the tiny sounding rockets, which we were launching back then, the country has gone on to develop and produce SLV3, ASLV, PSLV and GSLV, launch vehicles capable of lofting a variety of payloads into different type of orbits. These have gone into Low Earth Orbits (LEO), Geosynchronous orbits, Lunar and Martian orbits.

Numerous spacecraft with varying missions to serve the nation are continuously providing information on resources, climate, geographical images, security-related inputs, agriculture and forestry.

Communication and television services are carried to every nook and corner of the country with our own satellites. They are part of the worldwide internet services and mobile telephony which connect continents seamlessly at virtually negligible cost.

India has risen to rank among the top half a dozen nations with mastery over all aspects of space technology and its applications. The various branches of the government make use of the services provided by ISRO, including the planning commission, the defence services, information and broadcasting services and others.

ISRO, apart from launching its own spacecraft has been regularly launching spacecraft for other countries on a commercial basis with a high degree of reliability.

ISRO has been hailed as a model government run technical organization which has delivered on its promises and has gained a reputation for cost effectiveness, dependability and quality.

Vikram Sarabhai was alive only for the first of the six decades of ISRO's existence, but undoubtedly, he himself would have been surprised to observe the spectacular progress achieved in his favourite initiative. Not only have the objectives set by him been achieved, but also exceeded in a large measure. Highly competent and professional expertise has been created, moulded from the human resources available across the country, mostly from average colleges and institutions. Their output has been as excellent as anywhere else in the world. For example, the PSLV rocket in its various configurations has until December 2019, successfully launched, according to the present Chairman, ISRO, ' 52.7 tonnes of a variety of satellites into different orbits, out of which $17 \%$ have 
been for foreign customers'. The reliability of this vehicle rivals the best in the world, having achieved a reliability of more than $96 \%$ out of 50 launches!

Certainly, stalwarts like M. G. K. Menon, Satish Dhawan, U. R. Rao, Kasturirangan and others who carried the torch forward, guided the organization through its triumphs and achievements, but it was Sarabhai's bold vision and the initial managerial excellence which set the course ahead and continued to inspire the young scientists to carry on with determination.

In the digital world of today, we talk of 'start-ups' and their success, but the most spectacular story of a start-up which has been resoundingly successful is that of ISRO. I was fortunate to have been among the first, handful of young men to be personally recruited by Sarabhai to form the core team for starting space-related activities in the country. I have seen at first hand, the growth of the organization to the present day, having taken active part in almost all aspects of ISRO's work and have never ceased to be amazed by the successful crossing of milestone after milestone over the decades. I have described the story of this success elsewhere in my book, ISRO, A Personal History, Harper Collins, 2017.

The beginnings of space activity in India were rather modest. Although he came from a rich business family, Sarabhai had decided to pursue a career in physics. He was a student of the legendary C. V. Raman. After obtaining a degree from Cambridge he had set up the Physical Research Laboratory (PRL) in Ahmedabad in the late 1950 s, already a hub of scientific activity.

Sarabhai was spearheading in the early sixties a project envisioned by a consortium of scientists from across the globe. They wanted to study the magnetic equator using sounding rockets. The magnetic equator is, like its cousin, the geographical equator, an imaginary line around the earth where its magnetic field becomes horizontal. It lies very close to the geographic equator. Scientists from all over the world wanted to launch rocket payloads from this region because they wanted to study a rather unique phenomenon: a strong belt of charged particles called the 'electrojet' which runs above the magnetic equator and has a great impact on worldwide radio communication. The study of this phenomenon could only be carried out in situ by instruments carried by sounding rockets.

Sites on the Kerala tip were found the best suited for locating such a rocket launching site. After inspecting several sites, Sarabhai and his advisors zeroed in on Thumba, a small fishing beach close to Thiruvananthapuram, the capital of Kerala. Thus, was born the nucleus of space research in India.

The initial activities of Thumba were under the umbrella of the Department of Atomic Energy and Homi Bhabha was an active participant in the enterprise. A core group of half a dozen young engineers and scientists were sent to NASA, USA for learning the ropes even before site acquisition was completed. A. P. J. Abdul Kalam, former President of India and I were amongst this first batch.

The rocket range had an area of around 600 acres and a sea front of about $2 \mathrm{~km}$. Launch pads were built facing the Arabian Sea. Fishermen continued to ply their nets on the beach, but reluctantly cleared the area during launchings. Facilities for the assembly of rockets, launchpads, block houses, a control centre, telemetry and tracking stations were set up, initially with a lot of help from Space Agencies from countries like USA, France and the then USSR. The range, formally called Thumba Equatorial Rocket Launching Station (TERLS), was dedicated to the United Nations for cooperative programmes with any member country. A variety of rockets and payloads were launched from TERLS by Indian and foreign scientists gathering valuable data.

Meanwhile, Sarabhai initiated programmes to produce all elements of sounding rockets and payloads indigenously so that Indian scientists need not depend on foreign agencies for resources. A series of sounding rockets called the Rohini Sounding Rockets were produced to reach different altitudes up to 500 to $600 \mathrm{~km}$.

While the focus was on sounding rocket activity, Sarabhai had envisioned the activation of long-term programmes for India's entry into satellite launching and its applications. The early 1960s saw the recruitment of the core group of engineers to commence development work on all subsystems of launch vehicles like propellants, materials, avionics, aerodynamics, propulsion, computation, miniaturization, fabrication techniques, systems reliability, ground support systems like telemetry, tracking, telecommand and so on. Pending commissioning of permanent laboratories and other facilities, available buildings like an old church with the bishop's house, an abandoned school building and abandoned dwellings of fishermen were used. The buildings of the fishing village had all been vacated as they were in the range of safety zones. Suitable new structures had been built on different beaches as a compensatory measure by the authorities. The newly formed groups started work on the design, development and testing of the various elements needed for an indigenous launch vehicle capability.

Satellite launching from Indian soil needed a much larger range, preferably east facing, to take advantage of the additional energy gained because of the earth's rotation. Sarabhai was able to convince the Andhra Pradesh government to make available a large area in the eastern coast of India, between Chennai city and Nellore. This island named Sriharikota was surrounded by the Pulicat Lake, the Bay of Bengal and the Buckingham Canal. It had an area of about 44,000 acres with a $50 \mathrm{~km}$ coastline. It was basically a scrub jungle with plantations of eucalyptus and casuarina trees developed by the government for fuel. Wild animals like jackals, wild boars and cattle roamed freely. Small groups of hunter-gatherer tribes 
known as the Yenadis lived in dispersed villages over the island.

I still remember the very first visit made by Sarabhai and some of us in the original team to the proposed launch site, sometime in May 1969. The team numbering about 30 to 40 persons including some officials of the local government had to travel some $25 \mathrm{~km}$ in sturdy jeeps across dry lake beds and sandy surfaces to reach the coastal stretch of the Bay of Bengal where the launch facilities were proposed to be located. Sarabhai, in his late 40s was energetically leading the team across the beach looking for suitable locations to build launch pads and control buildings. As he covered miles of beach by foot, showing no signs of fatigue, we could see the gleam in his eyes as if he could already visualize the busy world class space port this would become.

While the launch vehicle development groups were busy with the design of subsystems at Thiruvananthapuram, the sounding rocket launches continued from there. Meanwhile, the preparations for the satellite launching facilities at Sriharikota were initiated. Key personnel were identified for the design of a modest solid fuelbased Satellite Launch Vehicle (SLV) to put a small $(40 \mathrm{~kg})$ satellite into a $600 \mathrm{~km}$ circular orbit around the earth. Project teams were designated for each of the important subsystems and the teams set to work in earnest.

Developments of space applications were also afoot in Ahmedabad. An experimental station for receiving data from geosynchronous spacecraft launched by other countries was set up to gain experience. Use of such satellites for centralized broadcast of television, intercontinental telephone communication, etc. was brought under a collaborative programme so as to sensitize the government and other user agencies of the efficacy of such technology for the rapid development of the country.

Towards the end of the 1960s, Sarabhai who had taken over the role of Chairmanship of the Department of Atomic Energy in addition to Space, proposed the plans for the development profile in the field of space research for the decade 1970 to 1980 . Its conclusions in brief were as follows.

The programme envisages the establishment of the following for the decade 1970-80:

(1) Augmentation of the facilities for R\&D at the Space Science and Technology Centre to be able to build scientific and communication satellites and to environmentally test them.

(2) Facilities at the Space Science and Technology Centre for the development of inertial guidance systems and onboard miniaturized computers.

(3) Development at (SSTC, TIFR and ECIL) and construction of high-performance missile tracking radars and PCM communication systems for installation in the range and downrange stations.
(4) Construction of a plant for the manufacture of large solid propellant blocks and facilities for testing these blocks on the ground under simulated highaltitude conditions.

(5) Completion of a rocket fabrication facility for the manufacture of large sized rocket casings and hardware for rocket motors including the development of special materials.

(6) Developing by 1974-75 a launcher of four stages, burning solid propellant, capable of putting into orbit a satellite of about $30 \mathrm{~kg}$ payload. This would be followed by development of more advanced rocket systems capable of putting $1200 \mathrm{~kg}$ of payloads into synchronous orbits.

(7) Fabrication of communication satellites by 1975 capable of providing high quality point to point telecommunication service between metropolitan areas and direct broadcast of television.

(8) Development of sensors and techniques for remote sensing.

Sarabhai also stated that the constraints of the development of space technology are related to the development of men and teams familiar with the new sophisticated technology. With a growth rate of $50 \%$ to $100 \%$ per year, we would still need about three years before reaching the minimum critical size for successfully implementing large scale projects of space technology.

Almost 50 years after these proposals were made and approved by the government, if I look back, I see that everyone of the tasks proposed has been completed and we have gone much beyond. Inspired leaders who followed Sarabhai after his premature death in December 1971 carried out elements of his vision with dedication and with the total involvement of the huge pool of manpower created over the decades. Some initial failures did not deter the organization from learning from them and going forward to successfully achieve the goals he set forth. More than the technology that has been generated, Sarabhai and his successors have created a vibrant organization, unfettered by red tape and hierarchical structures, able to make bold commitments and strive hard to deliver on them. No wonder that ISRO has often been cited as a model organization under government control which has succeeded.

An old saying goes, 'those whom the gods love die young'. This was true in the case of Vikram Sarabhai. He passed away at the age of 52 in Thiruvananthapuram, his favourite place where he lovingly created an outstanding organization. I still remember the fateful day when he breathed his last at the lovely Halcyon Castle guest house in Kovalam.

It was the 29 December 1971, Sarabhai had visited Thumba and the Veli Hills laboratories for his monthly reviews of progress and proceeded to his place of stay at Kovalam where, as usual, the discussions and meetings 
would continue long into the night. This time the plans for the development of SLV launch vehicle and its various subsystems as well as the details of the constructions at Sriharikota were the leading subject of discussions. I remember the scene at the makeshift conference hall at the Halcyon Castle where we jostled with each other to present our plans. My project, which was the establishment of the radar tracking and telemetry systems at SHAR, was presented to him. It was almost midnight and when I left for home, Sarabhai was still discussing with some of my colleagues. He was a very light sleeper and irrespective of the time he went to sleep, would rise at the crack of dawn and when at Kovalam, would have an early morning swim in the sea.

At around 6 a.m. in the morning as I was just about to get out of bed, the phone rang. It was the local PTI correspondent whom I knew. He was frantically asking me whether it was true that Sarabhai had suddenly passed away at Kovalam the previous night! I thought it was some cruel joke since I was personally with him well past midnight and he seemed perfectly fine. Soon I got another call from my PA confirming the sad news that Sarabhai had suffered a massive brain haemorrhage and was no more. I rushed to Kovalam which was about $12 \mathrm{~km}$ from where I stayed, and as I reached the gates of the hotel, I saw groups of my colleagues standing around in a daze. I hesitantly walked into the bed room and saw the muchloved kurta and pyjama clad figure of Sarabhai lying on the bed. He seemed to be asleep. He wore an expression of peace - almost as if he knew that he had completed his share of the tasks satisfactorily and handed them over to others to carry on.
And 'carry on', we did over the next almost half a century! I personally have grown along with ISRO since those days when it was a mere idea in a visionary's mind, through its phenomenal transformation into the veritable giant it is today. I have seen successive leaders steering it through the exciting phases almost seamlessly. Technical expertise and leadership have sprung from its workforce, as if by magic, to carry the torch forward. Failures have been converted to rich learning experiences followed by eventual triumphs. I have sat in control rooms with accelerating heart beats when bold new missions like Chandrayan and Mangalyan had taken off and shared the exhilaration when the missions succeeded. I have watched the politicians of the day proudly acclaiming ISRO's feats nationally and internationally, almost as if those were their personal achievement! I have gleefully noted the reluctant acceptance of the achievements of ISRO by advanced countries who were unwilling to share their knowhow with us.

And we are nowhere near the end of our story. We have lofted heavy payloads into distant orbits with our own rockets, carrying the state-of-the-art spacecraft. Much beyond what Sarabhai envisaged, we have gone beyond earth orbit to explore our neighbouring planets. We have plans to explore the Sun and have embarked on plans to carry Indian astronauts aboard manned spacecraft launched with our rockets from our own soil.

This will be a fitting tribute to the man who started it all!

doi: $10.18520 / \mathrm{cs} / \mathrm{v} 118 / \mathrm{i} 8 / 1199-1202$ 